\title{
Length Variation of Toothed Belt During Exploitation
}

\author{
Blaza Stojanović 1,* $^{*}$ Nenad Miloradović ${ }^{1}$ - Nenad Marjanovic ${ }^{1}$ - Mirko Blagojević ${ }^{1}$ - Lozica Ivanović ${ }^{1}$ \\ ${ }^{1}$ University of Kragujevac, Faculty of Mechanical Engineering from Kragujevac, Serbia
}

Timing belt drives represent a relatively new concept in power transmission, accepted nowadays in all areas of industry. Teeth, equally spaced on the inner side of timing belts, come into a contact with belt pulley's teeth through their grooves. By this meshing, a connection between the belt and the belt pulley is achieved and torque is transmitted.

This paper reviews basic tribomechanical systems in timing belt drives, focusing on the analysis of tribomechanical system "belt's teeth - belt pulley's teeth". In addition, analysis of pitch variation and belt's length variation during testing is conducted. Friction is the main cause of wear of the flanks of the belt's teeth, which leads to increase of pitch. Testing of the timing belt was conducted on a specially designed test bench and it showed that the belt's elongation is especially distinct in a period of running in.

(c)20xx Journal of Mechanical Engineering. All rights reserved.

Keywords: timing belt drives, belt pitch, friction, wear, tribology, tribomechanical systems

\section{INTRODUCTION}

Timing belt drive is relatively young drive designed by Richard Y. Case in 1946 [1]. It was a rubber belt with trapezoidal teeth profile used as a transmitter on a sewing machine. Despite the advantages in operation, timing belt drives have just recently gained large application. It was not until the application of timing belts as IC engine's camshaft drive, that usefulness of their application became obvious. The intensification of design demands from the aspects of increase of service life and decrease of construction's mass have initiated the appearance of a large number of tests of timing belt drives $[2,3]$.

Gerbert at al. [4] formed the first model of timing belt and conducted a detailed analysis of forces acting on the belt teeth. They introduced friction force into the analysis of load distribution. Further steps in analysis of these transmitters were achieved by testing of their tractive characteristics [5], by analysis of load distribution and by pretension of the timing belt [6, 7]. Kido at al. [8] presented the first analysis of load distribution using the finite element method. Shortly after, the finite element method has been more and more introduced during analysis of timing belt drives. Karolev and Gold [9] presented a new, changed form of timing belt model. Analysis of load distribution takes into account the friction force and belt's deformation and tests are conducted under variable torque.

Considering more and more frequent use of timing belt drives, but also their limited service life, the analysis of friction and wear became more and more significant in the late 1990's. Dalgarno, Childs at al. [10, 11, 12, 13, 14, 15] introduced new models of timing belts, taking into account the friction force between belt's teeth and belt pulley, together with friction force analysed until then only between belt pulley's teeth apexes and the belt's groove. Dalgarno at al. gave detailed analyses of meshing and tribological processes on contact surfaces.

Introduction of friction force into a new model of belt $[16,17]$ and belt's model with mass $[18,19]$ showed that the results obtained by application of numerical methods completely coincide with experimental results, regarding load distribution. Paper [21] presents the analysis of deformation state through model developed by application of finite element method. Papers [22, 23] demonstrate the modelling of friction induced noise of timing belt drives.

Retrospective of the existing tests of timing belt drives is mostly related to analyses of meshing and load distribution, both analytical and numerical. The aim of this review is to identify basic tribomechanical systems in timing belt drive and analyze them. Wear that leads to increase of 
pitch and elongation of the belt appears as direct consequence of friction on the flanks of the belt and of the belt pulley. Elongation of the belt induces changes in kinematics of coupling and increased friction that brings about larger power losses, that is reduction of drive's efficiency.

\section{TRIBOMECHANICAL SYSTEM IN TIMING BELT DRIVES}

The largest amount of motion and power is transferred by shape, while only a small amount is transferred by friction. The influence of friction must not, by all means, be neglected. Appearance of friction in timing belt drives and its consequences have not been thoroughly explained. In contrast to other transmissions of power and motion (gears, chain drives, cardanic transmissions, etc.) in which friction mostly occurs in the contact of the two metal surfaces, in timing belt drives, there are one metal and one non-metal surface. The timing belt pulley of the tested timing belt drive is made of C45 steel (WNr 1.0503) with the initial teeth roughness of $R_{a}=1.6[\mu \mathrm{m}]$. The belt's material is rubber whose initial teeth roughness depends on measurement point (apex, flank or groove), i.e. $R_{a}=9 \div 12.5[\mu \mathrm{m}]$.

The basic tribomechanical systems in the timing belt drives are (Figure 1) [24]:

1. belt's tooth - belt pulley's tooth

2. belt's face - flange

3. the belt groove - apex of the belt pulley's tooth

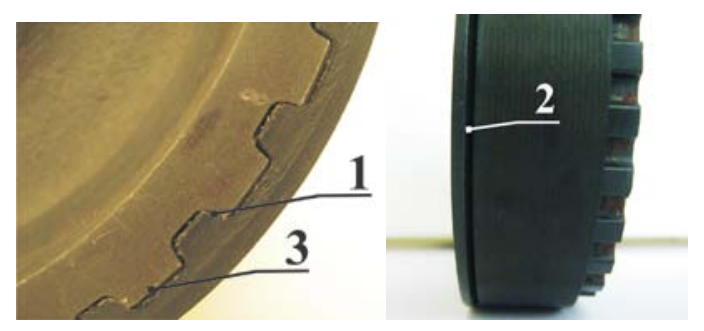

Fig. 1. Timing belt drive and basic tribomechanical systems

Types of motion that occur in these tribomechanical systems are given in Table 1.

The flank of the belt's teeth makes contact with the flank of the belt pulley's teeth, after entering the meshing. Besides, the inner surface of the belt groove and the outer surface of the belt pulley and, from time to time, the front surface of the belt pulley with the flange ring, are in contact.

Table 1. Tribomechanical systems and types of motion in timing belt drives

\begin{tabular}{l|c}
\hline Tribomechanical system & Type of motion \\
\hline $\begin{array}{l}\text { belt's tooth - belt pulley's } \\
\text { tooth }\end{array}$ & $\begin{array}{l}\text { - impact } \\
\text { - sliding } \\
\text { - rolling }\end{array}$ \\
\hline belt's face - flange & $\begin{array}{l}\text { - impact } \\
\text { - sliding }\end{array}$ \\
\hline $\begin{array}{l}\text { the belt groove - apex of } \\
\text { the belt pulley's tooth }\end{array}$ & - sliding \\
\hline
\end{tabular}

The belt's tooth enters the meshing with the drive belt pulley, maximally strained due to previous tension. During entering the meshing, the belt tooth's apex contacts the flank of the belt pulley's tooth. At that moment, a line contact occurs, i.e. pure roll occurs. Due to interference, the belt's tooth cuts into the flank of the belt pulley's tooth. Due to elastic properties of the belt and the large stiffness of the belt pulley, deformation of the belt's tooth occurs (Fig. 2, position 4). The usual initial assumption is that the belt pulley's stiffness is indefinitely large (rigid body) compared to the belt's stiffness [4, 9, 10, 15, 17]. Deformation of the belt's tooth grows, while, at the same time, the contact surface between the belt and the belt pulley's increases. The contact point between the belt's tooth and the belt pulley' tooth moves from the belt pulley's tooth apex towards its root.

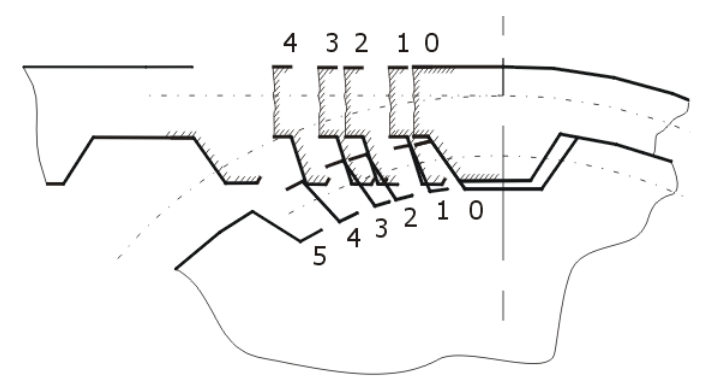

Fig. 2. Layout of belt's teeth entering the meshing with the teeth of the drive belt pulley 
Maximal tooth deformation takes place in position 2 (Fig. 2). The reduction of deformations occurs due to action of internal stresses and turning of the belt and the belt pulley. Full coincidence of the flanks of the belt's teeth and the belt pulley's teeth occurs in position 1 (Fig. 2). Now, contact over surface occurs. Relative sliding of their flanks, with appearance of the friction force, follows the process of belt's teeth entering the meshing with the belt pulley. The value of normal force varies according to parabolic law, which leads to variation of the friction force. The greatest values of normal force and friction force are at the teeth's roots.

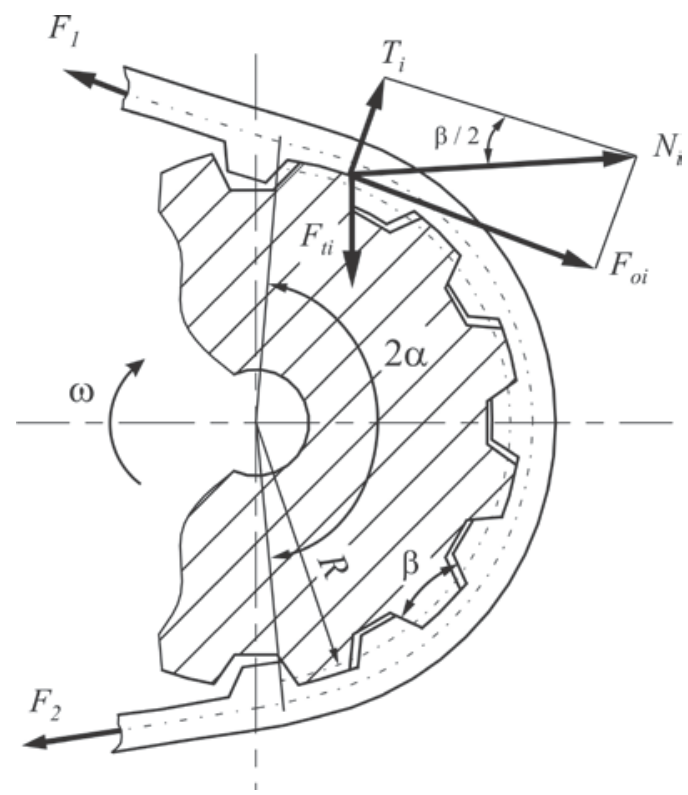

Fig. 3. Friction force at the flanks of the belt's tooth

Value of the friction force increases with the increase of the length of the sliding path and achieves its greatest value at the root of the belt's tooth (Figure 3). At the same time, the action point of the resultant component of normal force moves from the tooth's apex towards its root. The normal force changes according to parabolic law [25]:

$$
N_{i}=-\frac{N_{\max }}{l_{t}^{2}} \cdot\left(l-l_{t}\right)^{2}+N_{\max }
$$

where: $N_{\max }$ is maximal value of normal force ( $N_{\max } \approx 1.5 F_{o} / z_{01}$ ) and $l_{t}$ is the length of friction path.

The friction force occurs at the flank of the belt's tooth and its value is determined according to the following expression [25]:

$$
F_{t i}=N_{i} \cdot \mu=\frac{F_{o i} \cdot \mu}{\cos (\beta / 2)}
$$

where: $N_{i}$ is normal force acting on the belt's tooth, $\mu$ is the friction coefficient, $F_{o i}$ is circumferential force acting on the belt's tooth and $\beta$ is the angle of the belt's profile.

\section{TESTING OF TIMING BELT DRIVE}

Testing of timing belt drive was conducted on a specially designed test bench, made at the Laboratory for mechanical constructions and mechanization of the Faculty of mechanical engineering from Kragujevac. Test bench operates on a principle of opened loop power [26].

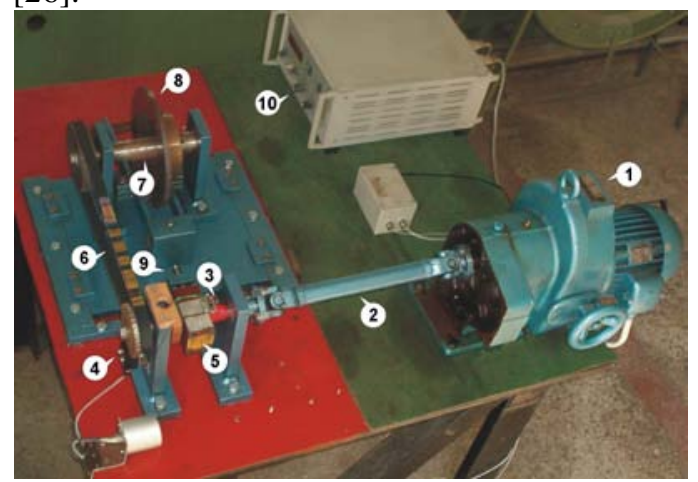

Fig. 4. Test bench for testing of timing belt 4, are:

Basic elements of the test bench, Figure

1. drive unit (electric motor),

2. cardanic drive,

3. measuring (input) shaft,

4. input shaft's rotational speed transducer,

5. input shaft's torque transducer,

6. tested drive (timing belt drive),

7. output shaft, 
8. mechanical brake,

9. tension mechanism and

10. amplifier bridge.

A toothed disc with 30 teeth on circumference is mounted on a measuring shaft. Rotational speed is read on amplifier bridge that acquires a signal from inductive sensor HBM M1 and rotational speed pulse receiver HBM DV2556. Shaft's torque is measured with contactless torque sensor that consists of a strain gauge, a signal transmitter HBM MT2555A and a signal receiver HBM EV2510A. Values of rotational speed and torque were displayed on a display of a digital amplifier DA24.

In order to obtain a true picture of tribological characteristics of the timing belt, measurement of roughness parameters and determination of geometrical values are conducted. Measurement of these values is conducted according to previously determined dynamics.

Before the tests began, the state of the contact surfaces and initial values of the belt's geometrical values were established. Further measurements were conducted after certain operation time and are shown in Table 2.
Table 2. Time intervals of measurement of roughness parameters and belt's geometrical values

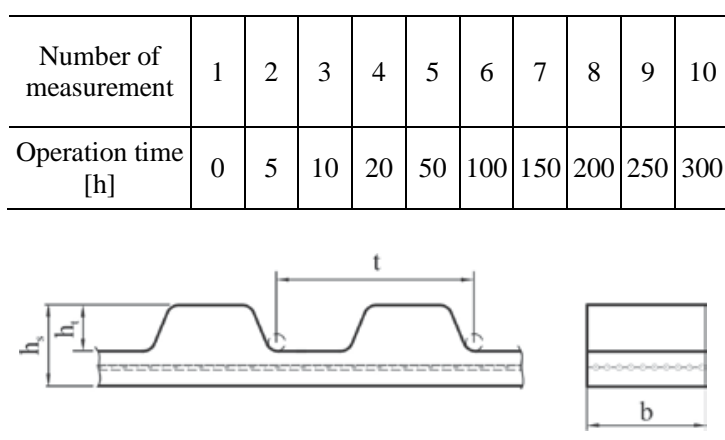

Fig. 5. Measured geometrical values of the belt

\section{VARIATION OF BELT'S PITCH}

Measurement of geometrical values of timing belts was conducted on eight belt's teeth. The following values were measured (Figure 4) [27]:

o belt's pitch $(t)$,

o belt's width $(b)$,

o belt groove's thickness $\left(h_{b}=h_{s}-h_{t}\right)$ and

o belt's total height $\left(h_{s}\right)$.

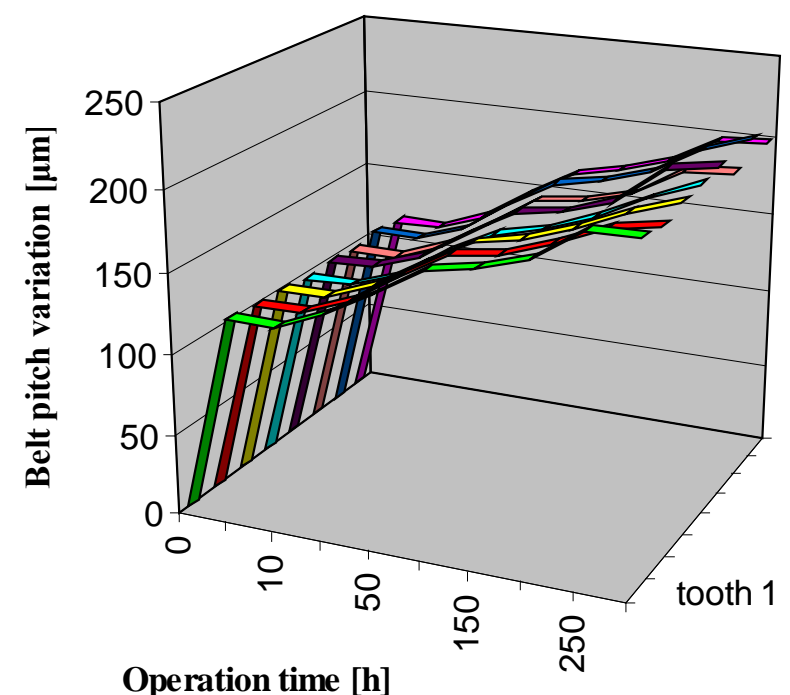

tooth 1

tooth 2

tooth 3

$\square$ tooth 4

$\square$ tooth 5

tooth 8

$\square$ tooth 6

$\square$ tooth 7

tooth 8

Fig. 6. Belt's pitch variation during exploitation 
Belt's pitch is a distance between centres of two consecutive teeth and it is measured on so-called pitch line. Considering the design realization of the belt and the available apparatus, the belt's pitch is measured at the tooth's root. Belt's pitch is determined with the rollers. Namely, the rollers having corresponding radii are set at the roots of the two successive belt's teeth (Figure 5). Then, the belt with the rollers is set on the auxiliary tool. The tension force exerted on the belt is the same for all measurements. The total length of the belt is determined based on the belt's pitch and the number of teeth. Measurement is conducted on optical microscope ZEISS ZKM01-250C.

Belt's pitch variation $(\Delta t)$ may be shown with the help of the following expression:

$$
\Delta t=t-t_{o}
$$

where: $t$ is measured value of belt's pitch during testing and $t_{o}$ is initial value of belt's pitch.

Measurement results of belt's pitch variation during operation for all eight teeth are given in Table 3 and shown in Figure 6.

Measurement results of belt's pitch variation during operation for all eight teeth are given in Table 3 and shown in Figure 6.

Table 3. Belt's pitch variation $\Delta t=t-t_{o}[\mu m]$

\begin{tabular}{|c|c|c|c|c|c|c|c|c|}
\hline \multirow{2}{*}{$\begin{array}{c}\text { Time of } \\
\text { operation } \\
\text { (hours) }\end{array}$} & \multicolumn{9}{|c|}{$\Delta t$} \\
\cline { 2 - 9 } & 1 & 2 & 3 & 4 & 5 & 6 & 7 & 8 \\
\hline 5 & 123 & 121 & 121 & 118 & 121 & 118 & 121 & 119 \\
\hline 10 & 123 & 122 & 121 & 119 & 120 & 118 & 121 & 119 \\
\hline 20 & 135 & 133 & 133 & 129 & 131 & 129 & 131 & 130 \\
\hline 50 & 152 & 152 & 151 & 148 & 150 & 147 & 151 & 150 \\
\hline 100 & 170 & 169 & 167 & 163 & 167 & 166 & 168 & 166 \\
\hline 150 & 175 & 174 & 173 & 170 & 172 & 170 & 174 & 173 \\
\hline 200 & 185 & 184 & 184 & 181 & 182 & 178 & 183 & 182 \\
\hline 250 & 204 & 197 & 197 & 196 & 205 & 196 & 201 & 198 \\
\hline 300 & 205 & 202 & 207 & 208 & 210 & 198 & 211 & 200 \\
\hline
\end{tabular}

Besides, the belt's length is obtained with the help of centre distance, by mounting of the same belt on the two belt pulleys having transmission ratio of 1 , with no previous tension. Values of the belt's length determined in both ways were approximately equal, before the belt was tested.

\section{ANALYSIS OF TRIBOLOGICAL PROCESSES}

In the period of running in, there is a sudden increase of belt's pitch. This increase originates from plastic deformation of the belt's tractive element and from wear of teeth's flanks. Wear by roll-formation (special form of elastomeric wear) is specially emphasized there and the consequences are removal of material from the belt's teeth and increase of pitch [28].

In the period of normal wear, which appears after 20 hours of operation, variation of geometrical values is still strong. After 20 hours of operation, the belt's pitch is still increasing. Variation of the belt's pitch is more pronounced in the period from 20 to 50 hours of operation, after which it becomes approximately linear. The results obtained by measurement on all eight teeth almost do not deviate one from another.

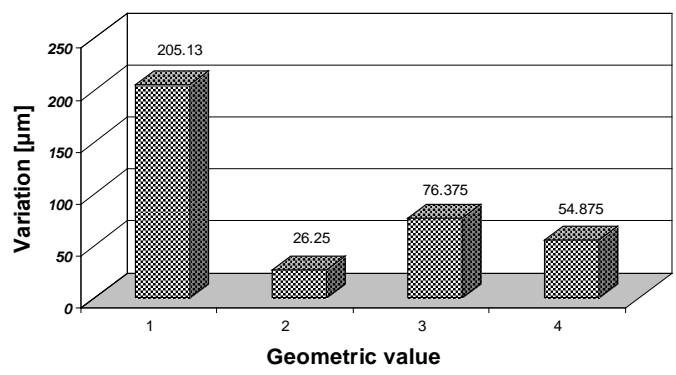

Fig. 7. Average values of variations of geometric values

1 - Belt' pitch

2 - Belt's width

3 - Belt's total height

4 - Belt groove's thickness

Absolute average values of variation of geometrical values are presented in figure 7 .

The histogram shows that the belt's pitch changes the most. The belt's pitch increases for approximately $0.2[\mathrm{~mm}$, which leads to the increase of the belt's length. Total elongation of the belt is approximately 23 [mm]. Increase of the belt's pitch induces variations in kinematics of coupling, reduction of contact surface, increase of friction and need for additional tightening. 
Variation of the belt's pitch arising in the period of running in is direct consequence of elongation of the tractive element, i. e. elongation of the belt. Thereat, the tractive element was permanently elongated. Elongation of the belt's pitch is the largest in the period of running (Table 2 ) and amounts $60 \%$ of total elongation. After the period of running in, during the period of normal wear, the belt's pitch was still increasing. The variation of the belt's pitch has almost linear form and it changes continuously until the end of the test. At the same time, the total length of the belt changes very little, i.e. the total variation of the belt's pitch is considerably larger than the variation of the belt's length. Newly created variation of pitch arises, in the first place, due to wear of the flanks of the teeth.

\section{CONCLUSIONS}

Increase of the belt's pitch arises due to plastic deformations of the belt's tractive element and wear by roll-formation of teeth's flanks. Increase of length (elongation) of the tractive element gradually occurs during exploitation and it permanently stays, even after the belt is unloaded. Large portion of this increase, approximately $70 \%$, is due to plastic deformation of the belt, while the rest of it is due to wear by roll-formation of the belt teeth's flanks. Participation of wear by roll-formation in total elongation of the belt increases with the increase of timing belt's operation time because plastic deformation is the greatest in the period of running in. Variation of the belt's pitch leads to disturbance in operation of timing belt. Namely, there are changes in load distribution, reduction of carrying capacity and unevenness in operation. There is a need for additional tensioning of the belt, which directly affects the service life of the drive.

\section{REFERENCES}

[1] Case, Y. R., Timing belt drive, McGraw Hill Book Company, INC, New York, 1954, p. 189.

[2] Stojanovic, B. (2007) Characteristics of tribological processes in timing belts (in Serbian), Master's thesis, Faculty of mechanical engineering from Kragujevac, Kragujevac.
[3] Stojanovic, B., Miloradovic, N. Development of timing belt drives, Mobility and Vehicle Mechanics, 2009, vol. 35, no. 2, p. 31-36.

[4] Gerbert, G., Jönsson, H., Persson, U., Stensson, G. Load distribution in timing belts. Trans. ASME, J. Mech. Des., 1978 vol.100, p. 208-215.

[5] Kagotani, M., Koyama, T., Hiroyuki, U., Aida, T., Hoshiro, T. Load distribution on toothed belt drives under a state of initial tension, Bull. Jap. Soc. Mech. Engrs, 1984, vol. 27, no 230, p.1780-1787.

[6] Metzner, D., Urbansky, N. Vorspannkraft bei zahnriemengetrieben, Maschinenbautechnik, 1984, vol. 33, p. 559-563.

[7] Naji, M. R., Marshek, K. M. Toothed belt load distribution. Trans. ASME, J. Mechanisms, 1983, vol.105, p. 339-347.

[8] Kido, R., Kusano, T., Fujii, T. Finite element analysis for distribution of toothed belts in two axes drive system (in Japanese). Trans. Jap. Soc. Mech. Engrs, 1995, vol. 61, p. 130136.

[9] Karolev, N. A., Gold, P.W. Load distribution of timing belt drives transmitting variable torque. Mech. Mach. Theory, 1995, vol. 30 no. 4, p. 553-567.

[10] Dalgarno, K. W., Day, A. J., Childs, T. H. C. Finite element analysis of synchronous belt tooth failure. Proc. Instn Mech. Engrs, Part D, Journal of Automobile Engineering, 1993, vol.207, p. 145-153.

[11] Dalgarno, K. W., Day, A. J., Childs, T. H. C. Synchronous belt materials and belt life correlation. Proc. Instn Mech. Engrs, Part D, Journal of Automobile Engineering, 1994, vol. 208, p. 37-48.

[12] Childs, T. H. C., Dalgarno, K. W., Hojjati, M. H., Tutt, M. J. The meshing of timing belt teeth in pulley grooves. Proc. Instn Mech. Engrs, Part D, Journal of Automobile Engineering, 1997, vol. 211, p. 205-218.

[13] Childs, T. H. C., Hojjati, M. H., Kohno, M., Nakamura, T. Land friction effects in the meshing of timing belts. Proc. Instn Mech. Engrs, Part J, Journal of Engineering Tribology, 1998, vol. 212, p.87-100.

[14] Childs, T. H. C., Dalgarno, K. W., Day, A. J., Moore R. B. Automotive timing belt life laws and a user design guide. Proc. Instn 
Mech. Engrs, Part D: Journal of Automobile Engineering, 1998, vol. 212, p. 409-419.

[15] Dalgarno, K. W., Day, A. J., Childs, T. H. C., Moore, R. B. Stiffness loss of synchronous belts. Composites, Part B, Engng J., 1998, vol. 29, p. 217-222.

[16] Johannesson, T., Distner, M. (1999) Model for tooth belt mechanics. Proceedings of 4th World Congress on Gearing and Power Transmission, Paris, 1999.

[17] Johannesson, T., Distner, M. Dynamic loading of synchronous belts. Trans. ASME, J. Mech. Des., 2002, vol. 124, p. 79-85.

[18] Callegari, M., Cannella, F. Lumpedparameter model of timing belt transmissions. Proceedings of 15th AIMETA Congress of Theoretical and Applied Mechanics, Taormina, Italy, 2001.

[19] Callegari, M., Cannella, F., Ferri, G. Multibody modelling of timing belt dynamics. Proc. Instn. Mech. Engrs. Part K: J. Multibody Dynamics, 2003, vol. 217, p. 63-75.

[20] Kagotani, M., Ueda, H., Koyoama, T. (2001) Transmission error in helical timing belt drives (case of a period of pulley pitch). Trans. ASME, J. Mech. Des., 2001, vol.123, p. 104-110.

[21] Zupancic, B., Nikonov, A., Florjancic, U., Emri, I. Time-dependent behavior of drive belts under periodic mechanical loading - an analysis of the location of a single line spectrum, Strojniski vestnik - Journal of mechanical Engineering, 2007, vol. 53, no. 10, p. 696-705.

[22] Sheng, G., Zheng, H., Qatu, M., Dukkipati, R. V. Modelling of friction-induced noise of timing belt, International Journal of Vehicle Noise and Vibration, 2008, vol.4, no.4, p. 285-303.

[23] Ueda, H., Kagotani, M., Koyama, T., Nishioka, M. Noise and Life of Helical Timing Belt Drives, ASME J. Mech. Des., 1999, vol.121, no. 2, p. 274-279.

[24] Stojanovic, B., Tanasijevic, S., Miloradovic, $\mathrm{N}$. Tribomechanical systems in timing belt drives, Journal of the Balkan Tribological Association, 2009, vol.15, no.4, p. 465-473.

[25] Vorobjev, I.I., Belt Drives (in Russian), Machine building, Moscow, 1979, 168 p.

[26] Stojanović, B., Miloradović, N., Blagojević, M. Analysis of Tribological Processes at Timing Belt's Tooth Flank, Tribology in Industry, 2009, vol.31, no. 3-4, p. 53-58.

[27] ISO 5296-1 (1989) Synchronous belt drives - Belts - Part 1: Pitch codes MXL, XL, L, H, $\mathrm{XH}$ and $\mathrm{XXH}$ - Metric and inch dimensions. Geneva, Internatonal Organization for Standardization.

[28] Aharoni, S.M., Wear of polymers by rollformation, Wear, 1973, vol. 25, no. 3, p. 309-327. 